\title{
We Need to Change: Integrating Psychological Perspectives Into the Multilevel Perspective on Socio-Ecological Transformations
}

\author{
Marlis C. Wullenkord ${ }^{* \dagger}$ and Karen R. S. Hamann ${ }^{\dagger}$ \\ Social, Environmental, and Economic Psychology, Department of Psychology, University of Koblenz-Landau, Landau, \\ Germany
}

Keywords: socio-ecological transformation, multilevel perspective, self-determination theory, self-efficacy theory, agency, socio-technical transitions, opinion, environmental psychology

\section{PSYCHOLOGY'S PLACE IN SOCIO-TECHNICAL TRANSITION RESEARCH}

\section{OPEN ACCESS}

Edited by:

Sonja Maria Geiger,

Justus Liebig University, Germany

Reviewed by:

Sebastian Bamberg

Bielefeld University of Applied

Sciences, Germany

Daniel Hanss,

Darmstadt University of Applied

Sciences, Germany

*Correspondence:

Marlis C. Wullenkord

wullenkord@uni-landau.de

tThese authors have contributed equally to this work and share first authorship

Specialty section:

This article was submitted to

Environmental Psychology,

a section of the journal

Frontiers in Psychology

Received: 18 January 2021

Accepted: 22 March 2021

Published: 26 April 2021

Citation:

Wullenkord MC and Hamann KRS

(2021) We Need to Change:

Integrating Psychological Perspectives

Into the Multilevel Perspective on

Socio-Ecological Transformations.

Front. Psychol. 12:655352.

doi: 10.3389/fpsyg.2021.655352

\begin{abstract}
"By embedding humans into systemic models [...] we can see that even when we are talking about global transformations, the source of intentional change is human thinking, feeling, and acting. Socio-ecologicaltechnological systems are created, ordered, and stabilized through human decision-making and (often) conscious creation of regime structures."-Göpel (2016, p. 50/51)
\end{abstract}

It sounds self-evident when Göpel explains how deeply ingrained humans are in transition processes. However, when working on a virtual lecture series called Psychologie des sozialökologischen Wandels (The Psychology of Socio-Ecological Change) ${ }^{1}$ we felt challenged when attempting to connect all parts into a consistent narrative on the connections of psychology and a socio-ecological transformation (i.e., the deep transformation of society aiming for decarbonization and socio-ecological justice, WBGU, 2011). With this challenge came ideas about transformation-oriented psychology that we feel inspired to share.

Previous research acknowledged that cultural worldviews and mindsets are essential for transformations (Meadows, 1999). The status quo and associated tangible structural outcomes are a result of human relationships and agency over time (Elias, 1982). Psychology as the study of human perception and behavior can contribute to transition research by investigating the processes underlying human agency. Nevertheless, psychological perspectives are rarely explicitly integrated into socio-technical transition research (Bögel and Upham, 2018). There have been pleas to clarify the role of individual-level processes in transitions (see Cattaneo et al., 2014; Bögel and Upham, 2018; Upham et al., 2020; Becker et al., 2021) and we personally experience a certain openness within psychology to do so. Kazdin (2009) even ascribes a crucial role to psychology in connecting different research areas. So why have those appeals only rarely been put into practice?

Environmental psychology historically focused on intra-individual factors (e.g., attitudes, control beliefs) and used them to explain pro-environmental behavior. As a result, it has been criticized for making somewhat mechanistic and reductionist assumptions, treating psychological constructs as isolated factors (see Dijk et al., 2016), and neglecting that contextual factors like larger-scale social structures and ecological processes influence behavioral outcomes (see Steg and Vlek, 2009). There are undeniable ontological and epistemological differences between psychological and transition science. Moreover, transformations are challenging to capture using psychological methods, and disciplinary research often

\footnotetext{
${ }^{1}$ https://ipu-ev.de/bildungsmaterialien/online-vorlesung/
} 
earns more (career) credits than interdisciplinary research. Nonetheless, we believe that psychological perspectives are crucial for transformations but that transition researchers will only integrate psychological perspectives if they consider processes and outcomes relevant for understanding transformations. Placing one's own research into transitionoriented approaches may be a challenging first step due to the difficulties inherent in interdisciplinary work, given the context-specificity of both the research object and transition research itself, and because it remains unclear how to do so in a meaningful way. Nevertheless, we present an attempt to make psychological perspectives more impactful through theoretical integration, using two psychological theories and an exemplifying transition-model (see current debate by Nielsen et al., 2021 and Van Valkengoed et al., 2021).

\section{A Multilevel Approach to Transformations}

There are several systemic models explaining socio-technical transitions, like the Multilevel Perspective (MLP, Geels and Schot, 2007, 2010) or the Multiphase Concept (Mersmann et al., 2014). One currently predominant model is the MLP (Geels and Schot, 2010). It looks at how socio-technical societal subsystems interact in transformation-processes across time and space: The landscape (macro-level; e.g., megatrends like climate change, the market system, hegemonic paradigms ${ }^{2}$ ), regimes (meso-level; e.g., policy, technology, science), and niches (microlevel). Higher levels-institutionalized, inertial, and historically rooted-are impactful but slow and difficult to change. Regimes are stabilized through path-dependencies like institutionalization or social-psychological infrastructures (e.g., norms, shared beliefs, see Welzer, 2011). They hamper individuals to imagine alternatives, lock the status quo, and prevent rapid change. Change occurs most readily in niches that provide safeguarded spaces to test radical socio-technical innovations. When regimes are destabilized, for instance because of landscape-level pressures like climate change, windows of opportunity open, and nicheinnovations can establish themselves in regimes. While the MLP is useful for understanding socio-technical innovations, it is difficult to pinpoint human agency in it (see Geels, 2011 for a discussion; see Winner, 1986 for a fundamental critique of a technology-focus as lever of change).

Göpel (2016) explicitly acknowledges individuals and hegemonic paradigms in transformations by adding two layers: The mini-level contains individuals making up institutions. The meta-level represents the "hegemonic paradigm and common sense framework that serves as a reference for individual strategies and narratives" of change (p. 47). Both levels interact: The mini-level influences the meta-level because every individual contributes to changing and shaping the future paradigm and thereby reality. The meta-level is deeply embedded in the meso-, micro-, and mini-levels and mediates between them. For instance, it affects how individuals in specific regimes think (cognitive lock-ins, see Welzer, 2011).

\footnotetext{
${ }^{2}$ i.e., predominant ways of thinking.
}

\section{THEORETICAL INTEGRATION OF PSYCHOLOGICAL CONSTRUCTS INTO GÖPEL'S MLP}

Interactions between the mini- and meta-levels are "the glue that holds societies together" (Göpel, 2016, p. 47) and can be promising research topics of a transformation-oriented psychology. Here, we exemplify with two psychological theories, namely Self-Determination Theory and Self-Efficacy Theory, how psychological perspectives could be embedded in Göpel's MLP (Göpel, 2016). Figure 1 depicts these thoughts.

\section{Self-Determination Theory}

Self-Determination Theory (Deci and Ryan, 2000; Ryan and Deci, 2017) is a humanistic, organismic-dialectical theory of human motivation. It proposes the universal, innate, basic psychological needs for autonomy (agency), competence (efficacy), and relatedness (belonging) as pre-requisites for healthy human functioning and self-sustaining, autonomous motivation. If these needs are frustrated rather than satisfied, humans become defensive, have difficulty integrating threatening information, and struggle to cope with challenges in proactive, healthy ways. Given that actors at all societal levels perceive the climate crisis and its subsequent implications for societal transformation as threatening and challenging, understanding basic psychological need satisfaction is critical (see Wullenkord, 2020).

Being a dialectical theory, Self-Determination Theory goes beyond the traditional individualistic approach of cognitive psychology and thereby fits well into transition-oriented ways of thinking. It proposes that need satisfaction is a function of the social context: Social contexts mediate in how far individuals or groups (e.g., activists in grassroots movements) can satisfy their needs. This, in turn, affects how individuals shape those contexts to be need-satisfying. For instance, the meso-level may set actual constraints in how far people can meet their needs (e.g., laws promoting social inequality may thwart need satisfaction), while the meta-level may influence how people perceive their needs to be met (e.g., narratives around growth-orientation represent need-frustrating, extrinsic values). Individual need satisfaction influences how individuals shape their proximate contexts, indirectly shaping niches and regimes, and contributing to the predominant way of understanding the world (meta-level).

\section{Self-Efficacy Theory}

Bandura's Self-Efficacy Theory (1997) arose as a critique of Skinner's (1971) behaviorism, assuming that humans are agentic beings that have the power to shape their surroundings (see Bandura, 2019 for a summary). Thus, Self-Efficacy Theory might be a suitable framework to investigate transformations in which individuals are not only the outcome of higher-level influences but actively create those settings as political agents. Self-efficacy is the belief that one is able to perform a specific behavior to produce certain outcomes (Bandura, 1997). Previous research has mainly considered behavioral self-efficacy (i.e., the belief that one can perform certain behaviors, Bandura, 2006a), in contrast to outcome expectancy (i.e., the belief that an action produces certain outcomes, Bandura, 1997). Perceived collective 


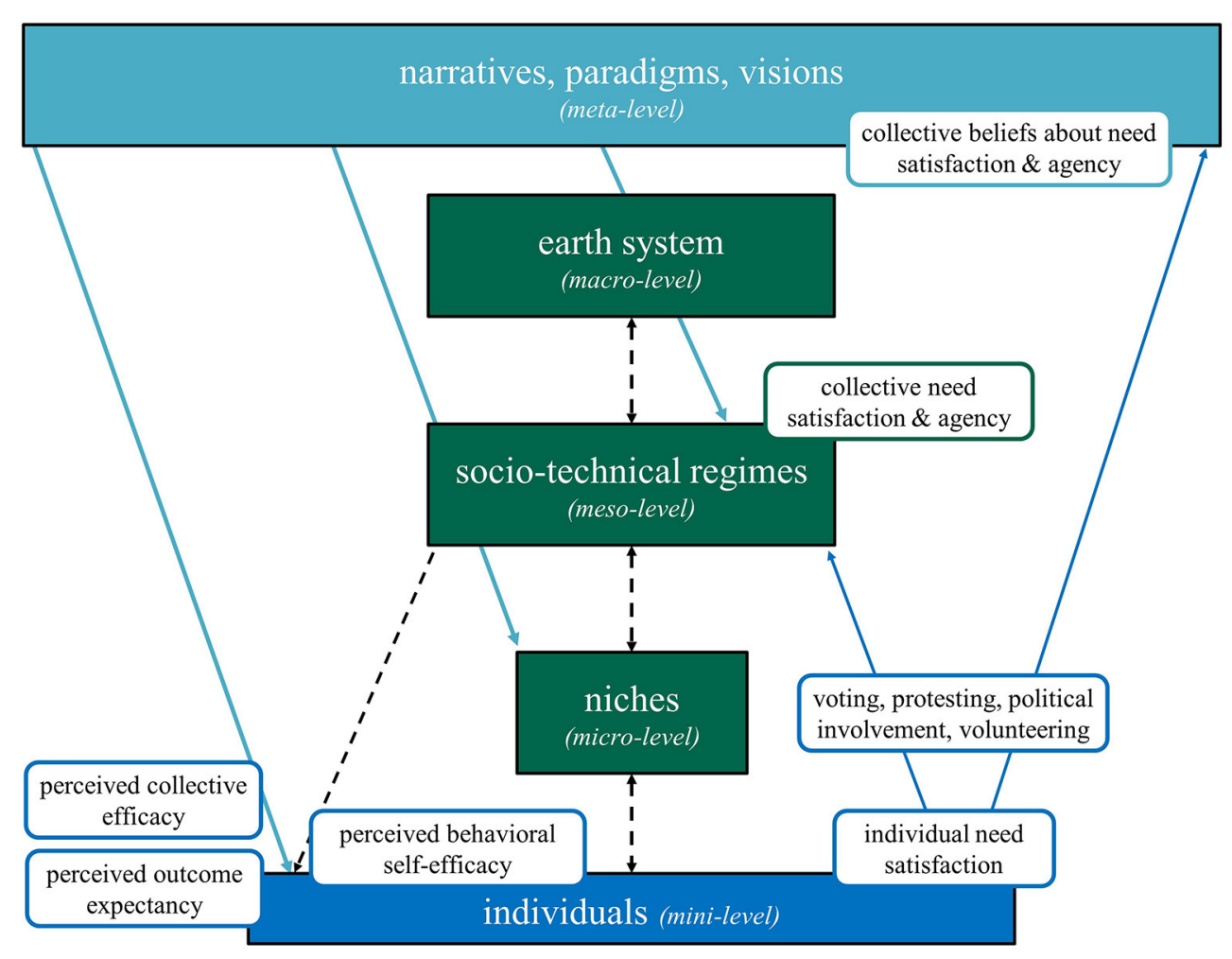

FIGURE 1 | Göpel's extended MLP. Arrows represent interactions between levels. In rounded rectangles, we exemplarily embed basic premises of Self-Determination Theory and concepts related to Self-Efficacy Theory (graphic adapted from Göpel, 2016, p. 47). The meta and meso-level set structural boundaries to individual need satisfaction and agency, and affect psychological perceptions such as beliefs about need satisfaction, collective efficacy, outcome expectancy, and behavioral self-efficacy. Psychological outcomes such as individual need satisfaction feed back into higher levels, for instance via voting, protesting, political involvement or volunteering (in niches). Collective need-satisfaction and actual collective and motivation arising from efficacy beliefs agency might be located at the meso-level. Collective beliefs about need-satisfaction and agency at the meta-level iteratively wield their influence on lower levels, such as individuals, their perceptions, and behavioral outcomes.

efficacy (i.e., the belief that a group agent can produce certain outcomes, Bandura, 1997) seems particularly important for collective change.

Self-efficacy affects people's aspirations, accomplishments, well-being, and perseverance in goal-pursuit in the face of difficulties (Bandura, 2006b, 2019). We hypothesize that behavioral self-efficacy evolves mostly from direct feedback and experiences made on the meso- and micro-level (e.g., regime lock-ins), while outcome expectancies and collective efficacy regarding societal transformations might be more strongly mediated by meta-level influences like success stories and visions as indirect social feedback (e.g., cognitive lock-ins). Even though Self-Efficacy Theory is primarily an individual-focused social cognitive theory, it may provide a basis for investigating actual (not only perceived) collective agency (see Empowerment Theory, Cattaneo and Chapman, 2010).

\section{DISCUSSION}

Based on the above considerations, we suggest how environmental psychology research could become more transition-oriented and exemplify how we may change our own research practices to contribute to socio-technical transition research. When we provide examples, we mainly focus on the university regime, even though a vast array of research topics is possible.

We need to develop and consider transformation-oriented concepts and connect them with psychological constructs and processes. To this end, we need to engage in the discourse on transition studies, set transformation-oriented research agendas that bridge systemic and individual perspectives, and phrase research questions accordingly. In the context of needs, one may ask "How do student initiatives as exemplary niches satisfy needs and thus foster autonomous motivation for long-term engagement, constantly recreating themselves to meet the needs of their members?" Further, "What influence does students' collective efficacy have on environmental intentions?" (Hamann and Reese, 2020, study 1) could become "What influence does students' collective efficacy have on a transformation of the university regime and how does the university regime in turn influence students' collective efficacy?"

We need to acknowledge real-life contexts as cause and consequence of individual behavior. To do so, we need to fit our theories to the contexts in which we use them. Even 
though criticized as reductionist and mechanistic (see Bögel and Upham, 2018), the Theory of Planned Behavior (Ajzen, 1991) is useful in contexts in which mindful decisions are possible. Yet in most contexts, theories bridging different levels might be more appropriate (e.g., value- and identity-oriented, dialectical theories, see Bamberg, 2018, Schulte et al., 2020). To acknowledge real-life contexts, we could focus on regime- or niche-specific research questions, include more long-term perspectives, and draw on data sets that are representative for specific contexts (see Brick, 2021 for a collection of openly available, largescale datasets). Moreover, we might apply methods from other disciplines to get a better picture of contexts. For example, to investigate students' collective efficacy in the university regime, we could examine university polls and university visions (meta-level) and collect data on university size and infrastructure (meso-level, e.g., complementing quantitative data collection with interviews). We would then not only examine individual behavioral outcomes but actual political change, changes in university narratives, participation processes, and the effectiveness of student actions.

We need to focus more on niches. Even though pioneer activity plays a crucial role in many transition models (e.g., Geels, 2011), it is largely underemphasized in environmental psychology. We need a discussion about niche groups, niche practices, and their respective influence (see Becker et al., 2021). For example, one may consider students' need satisfaction when participating in niches that aim to transform the university regime (e.g., install a green-office) and investigate psychological processes underlying long-term engagement.

We need to view individuals as political agents. Transition research has thus far mostly focused on technology acceptance and individuals as users or consumers (see Bögel and Upham, 2018; Köhler et al., 2019). By investigating individuals and groups as political agents, psychology could offer new perspectives to transition research with individual and collective levers of change. For example, studies could focus on university students as voters of a student parliament and active contributors to decisions relevant to what the cafeteria offers, instead of as mere consumers of (non)sustainable cafeteria products.

We need to have a disciplinary discourse about the interdisciplinary position of environmental psychology. The increasing amount of collaborative research teams (Kazdin, 2009) is a promising development and needs to be expanded (see

\section{REFERENCES}

Ajzen, I. (1991). The theory of planned behavior. Organ. Behav. Hum. Decis. Process. 50, 179-211. doi: 10.1016/0749-5978(91)90 020-T

Bamberg, S. (2018). Vom inaktiven Sympathisanten zum AktivistenGruppen-und Identitätsbildungsprozesse als Fokus umweltpsychologischer Forschung [From inactive sympathizer to activist: Group and identity formation processes as focus of environmental psychological research]. Umweltpsychologie (Zeitschrift Umweltpsychologie) 22, $150-159$.
Gifford, 2014). This development makes it even more important to discuss environmental psychology's place in research on socioecological transformation and necessary skills and resources connected to it at conferences, within research teams, or in theoretical articles (see Clayton et al., 2016).

We need to set a transformation-oriented research agenda. Large socio-ecological transformations could incorporate many new social practices (e.g., citizen participation, work time reduction, unconditional basic income). We might contribute to co-creating such protected spaces for niche practices in order to investigate them. For instance, we could set up living labs to explore how to deal with conflicting sustainability goals of various stakeholders (see Köhler et al., 2019).

We need to constantly rediscover our own curiosity about real-world processes. Finally, we propose to regularly question our own research in light of multidisciplinary theoretical and practical relevance, for instance by employing different, perhaps self-reflective methodological approaches.

\section{Conclusion}

In this opinion piece, we exemplified why and how to integrate our disciplinary perspective into the broader discourse on transitions, and discussed implications for environmental psychology research. Of course, our own view is limited and subject to discussion. We hope to stimulate such discussion and encourage readers to reflect on their own research practiceswith the overarching goal of understanding and promoting a socio-ecological transformation.

\section{AUTHOR CONTRIBUTIONS}

MW contributed the part on Self-Determination Theory. KH contributed the part on Self-Efficacy Theory. All authors contributed to the article and approved the submitted version.

\section{ACKNOWLEDGMENTS}

We would like to thank Parissa Chokrai, Benedikt Seger, Gerhard Reese (environmental psychology), Andreas Roos (human ecology), and two reviewers for their helpful comments on an earlier draft of this manuscript. We appreciate how their comments revealed a multitude of different opinions and enjoyed the thought-provoking but also challenging interdisciplinary discussion it sparked. and Company.

Bandura, A. (2006a). "Guide to construction of self-efficacy scales", in Self-Efficacy Beliefs of Adolescents, Vol. 5, eds F. Pajares and T. Urdan (Charlotte, NC: Information Age), 307-337.

Bandura, A. (2006b). Toward a psychology of human agency. Perspect. Psychol. Sci. 1, 164-180. doi: 10.1111/j.1745-6916.2006.00011.x

Bandura, A. (2019). Applying theory for human betterment. Persp. Psychol. Sci. 14, 12-15. doi: 10.1177/1745691618815165

Becker, S., Bögel, P. M., and Upham, P. (2021). The role of social identity in institutional work for sociotechnical transitions: the case of 
transport infrastructure in Berlin. Technol. Forecast. Soc. Change 162:120385. doi: 10.1016/j.techfore.2020.120385

Bögel, P. M., and Upham, P. (2018). Role of psychology in sociotechnical transitions studies: review in relation to consumption and technology acceptance. Environ. Innov. Soc. Trans. 28, 122-136. doi: 10.1016/j.eist.2018.01.002

Brick, C. (2021). Open Psychological Datasets. Available online at: https://docs.google.com/spreadsheets/d/1ejOJTNTL5ApCu GTUciV0REEEAqvhI2Rd2FCoj7afops/edit (accessed on January 14, 2021).

Cattaneo, L. B., Calton, J. M., and Brodsky, A. E. (2014). Status quo versus status quake: putting the power back in empowerment. J. Community Psychol. 42, 433-446. doi: 10.1002/jcop.21619

Cattaneo, L. B., and Chapman, A. R. (2010). The process of empowerment: a model for use in research and practice. Am. Psychol. 65, 646-659. doi: 10.1037/a0018854

Clayton, S., Devine-Wright, P., Swim, J., Bonnes, M., Steg, L., Whitmarsh, L., et al. (2016). Expanding the role for psychology in addressing environmental challenges. Am. Psychol. 71, 199-215. doi: 10.1037/a0039482

Deci, E. L., and Ryan, R. M. (2000). The "what" and "why" of goal pursuits: human needs and the self-determination of behavior. Psychol. Inq. 11, 227-268. doi: 10.1207/S15327965PLI1104_01

Dijk, M., Wells, P., and Kemp, R. (2016). Will the momentum of the electric car last? testing a hypothesis on disruptive innovation. Technol. Forecast. Soc. Change 105, 77-88. doi: 10.1016/j.techfore.2016.01.013

Elias, N. (1982). The Civilizing Process. New York, NY: Pantheon Books.

Geels, F. W. (2011). The multi-level perspective on sustainability transitions: responses to seven criticisms. Environ. Innov. Soc. Trans. 1, 24-40. doi: 10.1016/j.eist.2011.02.002

Geels, F. W., and Schot, J. (2007). Typology of sociotechnical transition pathways. Res. Policy 36, 399-417. doi: 10.1016/j.respol.2007.01.003

Geels, F. W., and Schot, J. (2010). "The dynamics of transitions: a socio-technical perspective," in Transitions to Sustainable Development: New Directions in the Study of Long Term Transformative Change, eds Schot, J., Grin, J., and Rotmans, J. (New York, NY: Routledge), 9-102.

Gifford, R. (2014). Environmental psychology matters. Annu. Rev. Psychol. 65, 541-579. doi: 10.1146/annurev-psych-010213-11 5048

Göpel, M. (2016). The Great Mindshift. How a New Economic Paradigm and Sustainability Transformations go Hand in Hand. Berlin: Springer.

Hamann, K. R. S., and Reese, G. (2020). My influence on the world (of others): goal efficacy beliefs and efficacy affect predict private, public, and activist pro-environmental behavior. J. Soc. Issues 76, 35-53. doi: 10.1111/josi.12369

Kazdin, A. E. (2009). Psychological science's contributions to a sustainable environment: Extending our reach to a grand challenge of society. Am. Psychol. 64, 339-356. doi: 10.1037/a0015685

Köhler, J., Geels, F. W., Kern, F., Markard, J., Onsongo, E., Wieczorek, A., et al. (2019). An agenda for sustainability transitions research: state of the art and future directions. Environ. Innov. Soc. Trans. 31, 1-32. doi: 10.1016/j.eist.2019.01.004

Meadows, D. (1999). Leverage Points: Places to Intervene in a System. Lynedoch: The Sustainability Institute.
Mersmann, F., Wehnert, T., Göpel, M., Arens, S., and Ujj, O. (2014). Shifting Paradigms: Unpacking Transformation for Climate Action. Wuppertal: Wuppertal Institute for Climate, Environment and Energy.

Nielsen, K. S., Cologna, V., Lange, F., Brick, C., and Stern, P. C. (2021). The case for impact-focused environmental psychology. J. Environ. Psychol. 101559. doi: 10.1016/j.jenvp.2021.101559

Ryan, R. M., and Deci, E. L. (eds.). (2017). Self-Determination Theory: Basic Psychological Needs in Motivation, Development, and Wellness. New York, NY: Guilford Press. doi: 10.1521/978.14625/28806

Schulte, M., Bamberg, S., Rees, J., and Rollin, P. (2020). Social identity as a key concept for connecting transformative societal change with individual environmental activism. J. Environ. Psychol. 72:101525. doi: 10.1016/j.jenvp.2020.101525

Skinner, B. F. (1971). Beyond Freedom and Dignity. New York, NY: Bantam Vintage.

Steg, L., and Vlek, C. (2009). Encouraging pro-environmental behaviour: an integrative review and research agenda. J. Environ. Psychol. 29, 309-317. doi: 10.1016/j.jenvp.2008.10.004

Upham, P., Bögel, P., and Dütschke, E. (2020). Thinking about individual actor-level perspectives in sociotechnical transitions: a comment on the transitions research agenda. Environ. Innov. Soc. Trans. 34, 341-343. doi: 10.1016/j.eist.2019.10.005

Van Valkengoed, A. M., Steg, L., Perlaviciute, G., Schultz, P. W., Brosch, T., Gatersleben, B., et al. (2021). Theory enhances impact. Reply to: 'The case for impact-focused environmental psychology'. J. Environ. Psychol. 101597. doi: 10.1016/j.jenvp.2021.101597

WBGU (2011). World in Transition. A Social Contract for Sustainability. Flagship Report. WBGU-German Advisory Council on Global Change, Bowling Green, $\mathrm{OH}$, United States. Available online at: https://www.wbgu.de/fileadmin/user_ upload/wbgu/publikationen/hauptgutachten/hg2011/pdf/wbgu_jg2011_en. pdf (accessed January 05, 2021).

Welzer, H. (2011). Mental Infrastructures: How Growth Entered the World and Our Souls. Berlin: Heinrich Böll Foundation.

Winner, L. (1986). The Whale and the Reactor: A Search for Limits in an Age of High Technology. Chicago, IL: The University of Chicago Press.

Wullenkord, M. C. (2020). Climate change through the lens of self-determination theory: how considering basic psychological needs may bring environmental psychology forward. Umweltpsychologie, (Zeitschrift Umweltpsychologie) 24, 110-129.

Conflict of Interest: The authors declare that the research was conducted in the absence of any commercial or financial relationships that could be construed as a potential conflict of interest.

Copyright (c) 2021 Wullenkord and Hamann. This is an open-access article distributed under the terms of the Creative Commons Attribution License (CC BY). The use, distribution or reproduction in other forums is permitted, provided the original author(s) and the copyright owner(s) are credited and that the original publication in this journal is cited, in accordance with accepted academic practice. No use, distribution or reproduction is permitted which does not comply with these terms. 